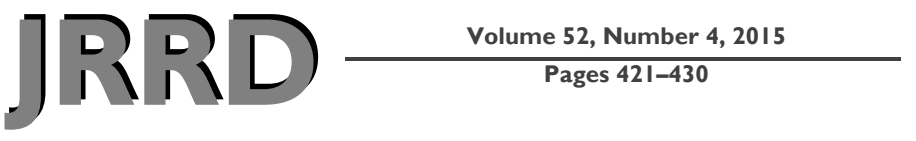

\title{
Immediate video feedback on ramp, wheelie, and curb wheelchair skill training for persons with spinal cord injury
}

\author{
Yong Tai Wang, PhD; ${ }^{*}$ Weerawat Limroongreungrat, PhD, PT; ${ }^{2}$ Li-Shan Chang, PhD, PT; ${ }^{3}$ Xiang Ke, MS; \\ Liang-Ching Tsai, PhD, PT; ${ }^{5}$ Yu-Ping Chen, ScD, PT; ${ }^{5}$ James Lewis, PT, DPT, ATC ${ }^{6}$ \\ ${ }^{1}$ College of Nursing and Health Sciences, University of Texas at Tyler, Tyler, Texas; ${ }^{2}$ College of Sports Science and \\ Technology, Mahidol University, Salaya, Thailand; ${ }^{3}$ Department of Rehabilitation, Shin Kong Wu Ho-Su Memorial \\ Hospital, Taipei, Taiwan; Departments of ${ }^{4}$ Health and Kinesiology and ${ }^{5}$ Physical Therapy, Georgia State University, \\ Atlanta, Georgia; ${ }^{6}$ Department of Physical Therapy, Brenau University, Gainesville, Georgia
}

\begin{abstract}
We hypothesized that the effects of immediate video feedback (IVF) on training ramp, wheelie, and curb wheelchair skills for persons with spinal cord injury (SCI) would be equivalent to or better than the traditional wheelchair skill training. Participants were manual wheelchair users with recent SCI (thoracic 1-lumbar 1) who were matched (9 pairs) on motor function level, age, and sex and randomly assigned to a control group (conventional training) or an experimental group (IVF training). Participants learned three wheelchair skills and then went through the wheelchair skill competency test, retention test, and transfer test. Paired $t$-tests were used to examine the differences in training time (minutes), spotter intervention needed (counts), and successful rate in performance between the two groups. A 2 (groups) x 3 (skills) x 3 (tests) repeated-measures analysis of variance and Bonferroni adjustment test were used to examine differences between groups on wheelchair skills and tests. No differences were found between two groups in training times (minutes) on three wheelchair skills (experimental vs control: ramp $14.92+/-5.80$ vs $11.69+/-7.85$, wheelie $17.79+/-6.03$ vs $19.92+/-13.42$, and curb $38.35+/-23.01$ vs $48.59+/-15.21$ ). This study demonstrated that IVF for training manual wheelchair skills may produce similar results as the conventional training and may be an alternative training method for wheelchair skills.
\end{abstract}

Key words: conventional training, learning, manual wheelchair, physical therapy, rehabilitation, skill performance, spinal cord injury, verbal instruction, video feedback, wheelchair skill training.

\section{INTRODUCTION}

The ability to perform safe and effective wheelchair skills, such as wheelies and propulsion up and down a ramp or curb, plays an important role in daily mobility of full-time manual wheelchair users with spinal cord injury (SCI). According to the National Spinal Cord Injury Statistical Center, the median days hospitalized in a rehabilitation unit following SCI have been on a steady and significant decline [1]. With reduced rehabilitation time, patients with SCI who become full-time manual wheelchair users may not receive adequate wheelchair skill training before discharge. Therefore, it is important to develop more efficient training strategies for the wheelchair users with SCI to acquire wheelchair skills.

For conventional wheelchair skill training in wheelie, ramp, and curb techniques, clinical practitioners (e.g., physical therapists, occupational therapists, recreational

\footnotetext{
Abbreviations: ANOVA $=$ analysis of variance, IVF $=$ immediate video feedback, $\mathrm{L}=$ lumbar, $\mathrm{SCI}=$ spinal cord injury, $\mathrm{SD}=$ standard deviation, $\mathrm{T}=$ thoracic.

*Address all correspondence to Yong Tai Wang, PhD; 3900 University Blvd, College of Nursing and Health Sciences, BRB 2195, The University of Texas, Tyler, TX 75799; 903566-7075. Email: ywang@uttyler.edu http://dx.doi.org/10.1682/JRRD.2014.11.0286
} 
therapists, and peers) use such motor learning principles as demonstrations, verbal instructions, and physical assistance for patients [2-4]. With the advancement in rehabilitative technology, feedback such as biofeedback and/or visual feedback has been commonly used to facilitate learning [5-9]. Video demonstration and augmented feedback can provide knowledge of both movement (pattern) performance and movement results, and several studies have demonstrated the benefits of video feedback in individuals without SCI [10-12]. For example, videos have been widely used as a source of feedback for motor skill acquisition in sport performance [10,13-15].

Since the proprioception sensation may be impaired following SCI, individuals with SCI must adjust their body segments and the center of gravity of the body to accomplish wheelchair wheelie, ramping, or curbing performance through specific movement patterns based on their mobility. Theoretically, video feedback may help persons with SCI understand the spatial and temporal characteristics of the movement, visualize and assess their own performance, and compare their performance to expected movement patterns. As such, the use of video feedback is expected to enhance wheelchair skill learning and make wheelchair skill training more efficient by reducing the amount of time needed to achieve competency in performing wheelchair mobility safely and effectively.

While previous studies have shown promising results with incorporating video feedback in other patient populations, such as brain injury [16-17], research on the use of video feedback during rehabilitation for the SCI population is limited. Our study examined the effectiveness of using immediate video feedback (IVF) in a rehabilitation setting to train manual wheelchair users with SCI in learning three wheelchair skills: (1) propelling the wheelchair on an inclined surface, (2) stationary wheelies, and (3) ascending/ descending a curb. We hypothesized that the use of video feedback with attention-directing verbal instructions and cues (reminders in short phrases) during training in these wheelchair skills would result in the same or less training time to acquire similar wheelchair skill levels when compared with the conventional training.

\section{METHODS}

\section{Participants}

A total of 21 inpatients with SCI between thoracic (T)1 and lumbar (L)1 who had newly become full-time manual wheelchair users were recruited from Shepherd Center in Atlanta, Georgia, via flyers and posters, word of mouth, and physical therapists or other caregivers on the inpatient and outpatient services. Although the outpatients were encouraged to participate in this study, all participants were recruited from the inpatient service because of schedule conflicts and transportation issues for the outpatients. The inclusion criteria for participant selection were age 18 to $65 \mathrm{yr}$; use of a manual wheelchair as the primary means of mobility $(>80 \%$ of ambulation); SCI level T1 or below; and no previous training/ experience in performing wheelchair wheelie, ramp, and curb skills. Exclusion criteria included cognitive impairment that would limit the ability to sign a consent form or to participate, current upper-limb pain or injury limiting wheelchair mobility, or weight status that would hinder wheelchair mobility (body mass index of 30 or greater). Based on the data reported by Best et al. on the effects of implementing a wheelchair skills training program [2], a sample size of 20 (10 in each group) with an $\alpha$ level of 0.05 and assumed equal variance between groups would provide a statistical power greater than 80 percent to detect a significant between-group difference in wheelchair skills performance. Before the beginning of the study, participants signed consent forms and video release agreements that were approved by the Institutional Review Board for Human Subjects Testing from Georgia State University and the Shepherd Center.

\section{Group Allocation}

The participants were paired based on sex, age (18$30 \mathrm{yr}$ for the young group or 40-65 yr for the old group), and level of motor function (high paraplegia with motor loss from T1-T7 or comparable disability with loss of muscle function originating from $\mathrm{T} 1-\mathrm{T} 7$ vs low paraplegia with motor loss originating from T8-L1). For matching on motor function level, the differences in SCI level had to be within three intervals. For example, a participant with T1 would be paired with someone with SCI between $\mathrm{T} 1$ and $\mathrm{T} 3$, and a patient with T8 SCI would be paired with one between $\mathrm{T} 6$ and $\mathrm{T} 8$ or one between $\mathrm{T} 8$ and $\mathrm{T} 10$. The two members from each matched pair were randomly assigned to either the experimental or control group.

\section{Development of the Video "Model” Library}

A total of 17 experienced wheelchair users ( 9 female and 8 male) who had motor function level between T1 
and L1 and could safely and effectively perform the three wheelchair skills were recruited to develop a video model library. These experienced wheelchair users were videotaped while they performed the proper technique for each wheelchair skill [18-19]. These original videos (without verbal cues or computer graphic indications) from the experienced wheelchair users served as models to facilitate advanced wheelchair skill acquisition and the development of movement patterns in patients' early learning phase.

\section{Procedures}

The experimental group received IVF (Dartfish Software; Alpharetta, Georgia) for advanced wheelchair skill training. The control group learned the three wheelchair skills (ramping, wheelie, and curbing) using the conventional training method (i.e., with the feedback provided by the physical therapists). All participants were expected to go through four periods: training sessions, competency test, retention test, and transfer test. The ramp used for the wheelchair training/testing was $2.44 \mathrm{~m}$ long, $1.22 \mathrm{~m}$ wide, and had a 1:12 slope and a $1.83 \times 1.83 \mathrm{~m}$ top platform; the wheelie area was a circle with a diameter of $1.5 \mathrm{~m}$; and the curb was a $1.22 \times 1.22 \times 0.126 \mathrm{~m}$ platform.

\section{Advanced Wheelchair Skill Training}

The training sessions (approximately 30 min per session) were conducted twice a week until the participant mastered the skills. Participants were assigned to learn the three wheelchair skills in a random order and learned one skill in each session. At the beginning of each training session, all participants had 8 to 10 min for a warm-up, stretching the upper limbs, rotating the trunk, and pushing the wheelchair around. Next, the physical therapist/researcher gave verbal instructions and physical or video model demonstrations for learning and practicing a wheelchair skill. Then, the participants practiced the skill without verbal cues or physical assistance unless the physical therapist considered the participant's practice/performance unsafe. A spotter, safety strap, or belt was used to prevent the participant from tipping backward.

For participants in the control group, the physical therapists gave additional verbal feedback about correct performance and key errors based on observing the participant's practice. For those in the experimental group, the researchers first showed the participant and his or her physical therapist three skill example videos (one for each skill) of how the model (matched with the injury level, sex, and age) performed each skill. Then the participant practiced the skill, and his or her practice performance was recorded by the video cameras. Participants were videotaped with two Sony HDR-CX380 cameras (Sony; Tokyo, Japan) from the front and side views during their practice. Similar to how the physical therapists gave additional verbal feedback about correct performance and key errors based on observing the participant's practice for the control group, the participant was given the time to review his/her performance and the model's performance and identify the differences between his/her performance and the model's performance. The duration of feedback was approximately 5 to $7 \mathrm{~min}$ for both groups. Only the participant's practice time was counted for the training time; the duration of instruction and feedback were not counted for training time. During each training session, instruction was given first, and then practice and feedback were repeated until the participant grasped the skill and the competency test was conducted.

\section{Competency, Retention, and Transfer Test}

The competency test was administered after 3 to $4 \mathrm{wk}$ of training or when physical therapists considered that participants would be able to complete the skill safely based on their clinical judgment. To pass the competency test, participants were required to complete three consecutive successful attempts on a wheelchair skill safely and independently. The participants had three attempts on each skill during the competency test. For the ramping skill, a successful attempt meant the participant could successfully propel up and down the ramp at a relatively constant speed without tipping backward. For the wheelie skill, a successful attempt meant a successful take-off performance, maintaining the balance phase for $20 \mathrm{~s}$, and landing safely while remaining in the defined circle area. For the curbing skill, a successful attempt meant successfully ascending and descending the curb smoothly without the front rigging or casters hitting the curb or the ground and without tipping or losing balance. The following behaviors were considered unsuccessful attempts: incomplete performance, requirement of more assistance than a standby guard (for safety purpose) to accomplish the performance, or likelihood of being unsafe in the judgment of the physical therapist.

The retention test was administrated $1 \mathrm{wk}$ after the participants successfully passed the competency test. The location of the retention test and the settings of the ramp, curb, and cameras were the same as for the training 
sessions and the competency test. The participants began with a general warm-up, followed by performing the three skills. To pass the retention test, the participant was required to perform each of the three skills successfully and safely three times consecutively.

The transfer test was administered $1 \mathrm{~d}$ after the retention test. In this test, participants performed the skills in a different environment. The transfer test was conducted on a carpeted ramp for the ramping skill, on grass for the wheelie skill, and on a concrete curb for the curbing skill. To pass the transfer test, the participant was required to perform each of the three skills successfully and safely three times consecutively. The physical therapists administered all the tests with the researchers.

\section{Outcome Measures}

Progression in each skill acquisition was documented for each participant. The total time of training required to safely and successfully complete each skill performance of wheeling, curbing, and ramping skills was recorded. The time spent completing each wheelchair skill during each testing session was also recorded. The number of counts of spotter intervention and the successful rate of attempts for each wheelchair skill during training and testing sessions were also counted.

\section{Statistical Analysis}

Statistical analyses were performed using SPSS version 18.0 (IBM Corporation; Armonk, New York). Paired $t$-test was employed to examine the differences between the experimental and control group on learning and practice time (minutes), spotter intervention (counts), and rate of successful performance for each skill during each period $(p<0.05)$. A Wilcoxon matched-pair signed-rank (nonparametric) test was performed to confirm the difference between the groups on spotter intervention (counts) and rate of successful performance for each skill. A $2 \times 3 \times 3$ repeated-measures analysis of variance (ANOVA) and the Bonferroni post hoc test were used to examine the differences between the two groups on the three wheelchair skills and three tests in terms of time of skill performance, spotter intervention, and successful rate of performance.

\section{RESULTS}

Three participants ( 1 from the experimental and 2 from the control group) dropped out of the study for per- sonal reasons (relocation, schedule conflict, and transportation issue, respectively). As such, the data from a total of 18 participants, 9 pairs, were included for analysis. The demographic and clinical information on the two groups is presented in Table 1.

\section{Comparisons of Two Groups in Learning and Practice of Three Wheelchair Skills}

The means and standard deviations (SDs) of the training time needed and spotter intervention counts for the three wheelchair skills of the two groups are presented in Table 2. There was no significant difference between the experimental and control groups in the training time needed. For these new wheelchair users, the time required to master these wheelchair skills ranged from 11.69 to $48.59 \mathrm{~min}$. There was also no significant difference between the two groups in the spotter intervention (counts) on the three wheelchair skills in the paired test. However, the Wilcoxon matched-pair signed-rank test showed that the experimental group had significant less spot intervention ( $11.67 \pm 3.64$ vs $23.06 \pm 12.67$ counts) in curb skill in training session than the control group did.

\section{Competency, Retention, and Transfer Tests on Three Wheelchair Skills for Two Groups}

The means and SDs of the time needed to perform these three wheelchair skills in the competency, retention, and transfer tests are presented in Table 3. There were no significant differences between the two groups in the time to perform the wheelchair ramp skill and the curb skill during the competency, retention, and transfer tests. There was a significant difference $(p<0.05)$ in the time needed to perform the wheelchair wheelie skill during the competency test between the experimental group $(1.34 \pm 0.17 \mathrm{~min})$ and the control group $(2.05 \pm 0.76 \mathrm{~min})$

Table 1.

Demographic and clinical information of experimental group and control group. $N=9$ pairs.

\begin{tabular}{lcc}
\hline \multicolumn{1}{c}{ Demographic } & $\begin{array}{c}\text { Experimental } \\
\text { Group }\end{array}$ & $\begin{array}{c}\text { Control } \\
\text { Group }\end{array}$ \\
\hline Age, yr (mean \pm SD) & $33.2 \pm 12.7$ & $34.5 \pm 13.3$ \\
Female/Male & $3 / 6$ & $3 / 6$ \\
Body Mass, kg (mean \pm SD) & $78.6 \pm 14.4$ & $76.3 \pm 16.6$ \\
Sitting Height, cm (mean $\pm \mathrm{SD})$ & $84.8 \pm 5.0$ & $82.1 \pm 4.9$ \\
SCI Level & $\mathrm{T} 1-\mathrm{L} 1$ & $\mathrm{~T} 2-\mathrm{T} 12$ \\
\hline L= lumbar, SCI = spinal cord injury, SD $=$ standard deviation, $\mathrm{T}=$ thoracic. \\
\hline
\end{tabular}


Table 2.

Means and standard deviations of needed training time (in minutes) and spotter intervention (counts) of three wheelchair skills between two groups in paired $t$-test and Wilcoxon matched-pair signed-rank (nonparametric) test. $N=9$ pairs.

\begin{tabular}{lccc}
\hline \multicolumn{1}{c}{ Group } & Ramp & Wheelie & Curb \\
\hline Learn and Practice (min) & $14.92 \pm 5.80$ & $17.79 \pm 6.03$ & $38.35 \pm 23.01$ \\
$\quad$ Experimental & $11.69 \pm 7.85$ & $19.92 \pm 13.42$ & $48.59 \pm 15.21$ \\
$\quad$ Control & $0.41 \pm 0.45$ & $18.00 \pm 10.94$ & $11.67 \pm 3.64^{*}$ \\
Spotter Intervention (counts) & $1.60 \pm 2.93$ & $12.00 \pm 11.92$ & $23.06 \pm 12.67^{*}$ \\
$\quad$ Experimental & & \\
Control & & \\
\hline "Significance at $p<0.05$ level in Wilcoxon matched-pair signed-rank test.
\end{tabular}

Table 3.

Means and standard deviations of performance time (in minutes) on competency, retention, and transfer tests of three wheelchair skills between two groups in the paired $t$-test. $N=9$ pairs.

\begin{tabular}{lccc}
\hline \multicolumn{1}{c}{ Group/Skill } & Competency & Retention & Transfer \\
\hline Ramp & & & \\
$\quad$ Experimental & $0.57 \pm 0.24$ & $0.59 \pm 0.23$ & $1.06 \pm 0.29$ \\
$\quad$ Control & $0.76 \pm 0.25$ & $0.65 \pm 0.20$ & $1.10 \pm 0.30$ \\
Wheelie & & & \\
$\quad$ Experimental & $1.34 \pm 0.17^{*}$ & $1.55 \pm 0.34$ & $1.32 \pm 0.13$ \\
$\quad$ Control & $2.05 \pm 0.76^{*}$ & $1.71 \pm 0.65$ & $1.40 \pm 0.48$ \\
Curb & & & \\
$\quad$ Experimental & $1.84 \pm 0.41$ & $1.60 \pm 0.53$ & $3.30 \pm 0.79$ \\
Control & $2.00 \pm 1.15$ & $2.40 \pm 1.52$ & $3.76 \pm 2.40$ \\
\hline Significance at $p<0.05$ level. & & \\
\hline \hline
\end{tabular}

but not during the retention and transfer tests. The means and SDs of spotter intervention (counts) and of safe and successful performance $(\%)$ of the three wheelchair skills are presented in Table 4 . There were no significant differences between the two groups in spotter interventions and success rate on the wheelchair ramp and wheelie skills during the competency, retention, and transfer tests. However, on the wheelchair curb skill, the experimental group had significantly more spotter interventions during the transfer test $(6.08 \pm 1.38$ counts $)$ than the control group (4.63 \pm 1.09 counts), and the experimental group $(42.86 \% \pm 34.50 \%)$ also had a significantly lower success rate during the transfer test than the control group $(82.14 \% \pm 18.90 \%)$.

\section{Comparisons of Two Groups, Time of Skill Performance, Spotter Interventions, and Rate of Successful Skill Performance in Three Tests}

The results of 2 (groups) $\times 3$ (skills) $\times 3$ (tests) repeatedmeasures ANOVA are presented in Table 5. Overall, there were no significant differences in skill performance time, spotter interventions, or rate of successful performance between the two groups. There were significant differences in performing these three wheelchair skills. The ramp performance time was significantly shorter than the wheelie performance time $(0.79 \pm 0.09$ vs $1.56 \pm 0.33 \mathrm{~min}$, $p<0.01)$ and the curb performance time $(0.79 \pm 0.09$ vs $2.53 \pm 0.80 \mathrm{~min}, p<0.01)$. There were significantly more curb spotter interventions $(p<0.01)$ than wheelie spotter interventions $(3.21 \pm 1.00$ vs $1.09 \pm 1.14$ counts, $p<0.01)$ and ramp spotter interventions $(3.21 \pm 1.00$ vs $0.00 \pm$ 0.00 counts, $p<0.01$ ). The successful rate of ramp performance was significantly greater than the rate of successful wheelie performance $(100 \% \pm 0 \%$ vs $86.05 \% \pm 11.03 \%$, $p<0.05$ ) and the successful rate of curb performance $(100 \% \pm 0 \%$ vs $71.71 \% \pm 5.46 \%, p<0.05)$. The successful rate of wheelie performance was significantly greater than the successful rate of curb performance $(86.05 \% \pm 11.03 \%$ vs $71.71 \% \pm 5.46 \%, p<0.05)$. There were also significant differences on the three tests. The transfer test time was significantly longer than the retention test time $(1.99 \pm$ 0.23 vs $1.42 \pm 0.32 \mathrm{~min}, p<0.05$ ). There were significantly more spotter interventions on the transfer test than on the retention test $(2.09 \pm 0.46$ vs $1.17 \pm 0.58$ counts, $p<$ $0.05)$ and the competency test $(2.09 \pm 0.46$ vs $1.05 \pm$ 0.54 counts, $p<0.01$ ). No significant difference was found on the rate of successful performance among the three tests.

\section{DISCUSSION}

\section{Comparisons between Two Groups in Learning and Practicing Three Wheelchair Skills}

This study examined the effectiveness of IVF on learning three advanced manual wheelchair skills in individuals with SCI. There was no significant difference in 
Table 4.

Means and standard deviations of spotter intervention (counts) and successful performance rate (\%) on competency, retention, and transfer tests of three wheelchair skills between two groups in paired $t$-test. $N=9$ pairs.

\begin{tabular}{|c|c|c|c|}
\hline Group/Skill & Competency & Retention & Transfer \\
\hline \multicolumn{4}{|c|}{ Ramp Spotter Intervention (counts) } \\
\hline Experimental & $0 \pm 0$ & $0 \pm 0$ & $0 \pm 0$ \\
\hline Control & $0 \pm 0$ & $0 \pm 0$ & $0 \pm 0$ \\
\hline \multicolumn{4}{|l|}{ Ramp Successful Rate (\%) } \\
\hline Experimental & $100 \pm 0$ & $100 \pm 0$ & $100 \pm 0$ \\
\hline Control & $100 \pm 0$ & $100 \pm 0$ & $100 \pm 0$ \\
\hline \multicolumn{4}{|c|}{ Wheelie Spotter Intervention (counts) } \\
\hline Experimental & $1.0 \pm 1.4$ & $1.1 \pm 1.7$ & $0.8 \pm 1.2$ \\
\hline Control & $1.1 \pm 1.6$ & $1.4 \pm 1.6$ & $1.0 \pm 1.3$ \\
\hline \multicolumn{4}{|c|}{ Wheelie Successful Rate (\%) } \\
\hline Experimental & $87.1 \pm 16.8$ & $79.1 \pm 16.6$ & $100 \pm 0$ \\
\hline Control & $77.9 \pm 22.0$ & $81.4 \pm 18.4$ & $90.7 \pm 16.4$ \\
\hline \multicolumn{4}{|c|}{ Curb Spotter Intervention (counts) } \\
\hline Experimental & $2.2 \pm 0.8$ & $1.9 \pm 1.3$ & $6.1 \pm 1.4^{*}$ \\
\hline Control & $2.0 \pm 1.2$ & $2.4 \pm 2.6$ & $4.6 \pm 1.1^{*}$ \\
\hline \multicolumn{4}{|l|}{ Curb Successful Rate (\%) } \\
\hline Experimental & $69.7 \pm 6.8$ & $71.4 \pm 22.5$ & $42.9 \pm 34.5^{*}$ \\
\hline Control & $82.0 \pm 21.1$ & $82.1 \pm 23.8$ & $82.1 \pm 18.9^{*}$ \\
\hline
\end{tabular}

Table 5.

Means and standard deviations of two groups, three skills, and three tests on learning and practicing time (minutes), spotter intervention (counts), and successful performance rate $(\%)$ in $2 \times 3 \times 3$ repeated-measures analysis of variance. $N=9$ pairs.

\begin{tabular}{lccc}
\hline Group/Skill/Test & Time of Skill Performance & Spotter Intervention & Successful Rate of Performance \\
\hline Groups & $1.46 \pm 0.15$ & $1.45 \pm 0.62$ & $83.37 \pm 4.23$ \\
$\quad$ Experimental & $1.79 \pm 0.48$ & $1.42 \pm 0.39$ & $88.47 \pm 6.58$ \\
$\quad$ Control & $0.79 \pm 0.09^{*}$ & & \\
Skills & $1.56 \pm 0.33^{*}$ & $0.00 \pm 0.00^{*}$ & $100.00 \pm 0.00^{*}$ \\
$\quad$ Ramp & $2.53 \pm 0.80^{*}$ & $1.09 \pm 1.14^{*}$ & $86.05 \pm 11.03^{\dagger}$ \\
Wheelie & & $3.21 \pm 1.00^{*}$ & $71.71 \pm 5.46^{*}$ \\
$\quad$ Curb & $1.47 \pm 0.80$ & & \\
Tests & $1.42 \pm 0.32^{\dagger}$ & $1.05 \pm 0.54^{*}$ & $86.12 \pm 6.31$ \\
Competency & $1.99 \pm 0.23^{\dagger}$ & $2.17 \pm 0.58^{\dagger}$ & $85.69 \pm 9.29$ \\
Retention & & & $85.95 \pm 6.93$ \\
$\quad$ Transfer & & \\
${ }^{*}$ Significance at $p<0.01$ level. & \\
†Significance at $p<0.05$ level. &
\end{tabular}

the time needed to learn and master these three wheelchair skills between the experimental and control groups. That meant the IVF and conventional physical therapy methods in learning these three manual wheelchair skills took similar amounts of time. In general, it took the participants 12 to 15 min to learn and master the ramping skill, 18 to
20 min to learn and master the wheelie skill, and approximately 40 to 50 min to learn and master the curbing skill. A few studies have reported the training time for a single wheelchair skill. For example, the training time for learning the curbing skill ranged from 42.5 to $87.4 \mathrm{~min}$ [18], and the training time for learning the wheelie skill ranged 
from 51.8 to $55.9 \mathrm{~min}$ in a high-rolling-resistance setting [19]. However, both these studies used nondisabled participants and the training time included instruction, warmup, and practice periods. In the present study, we only included practice time. We found that the ramping skill required the least time to learn, the curbing skill required the most time to learn, and the wheelie skill required a moderate time to learn. When we scrutinize general trends in the training time for these three wheelchair skills in the Figure, we can see an interaction in the training time across the three wheelchair skills. However, the experimental group had significantly less spot intervention for the curb skill in the training session than the control group did (Wilcoxon matched-pair signed-rank test, Table 2), which may indicate that the IVF may require less spot intervention in learning the curb skill for the person with SCI.

\section{Comparison Between Two Groups in Competency, Retention, and Transfer Tests of Three Wheelchair Skills}

Performance time on the wheelchair ramp skill did not significantly differ between the two groups across the three tests (Table 3); however, the transfer test time on the ramping skill was almost double that in the retention test. Therefore, transfer training in the wheelchair ramp skill may need to be emphasized. The control group took a significantly longer time on the wheelie skill than the experimental group in the competency test (Table 3). However, as participants went through the retention and transfer tests, this difference became insignificant. Performance time on the wheelchair curbing skill did not significantly

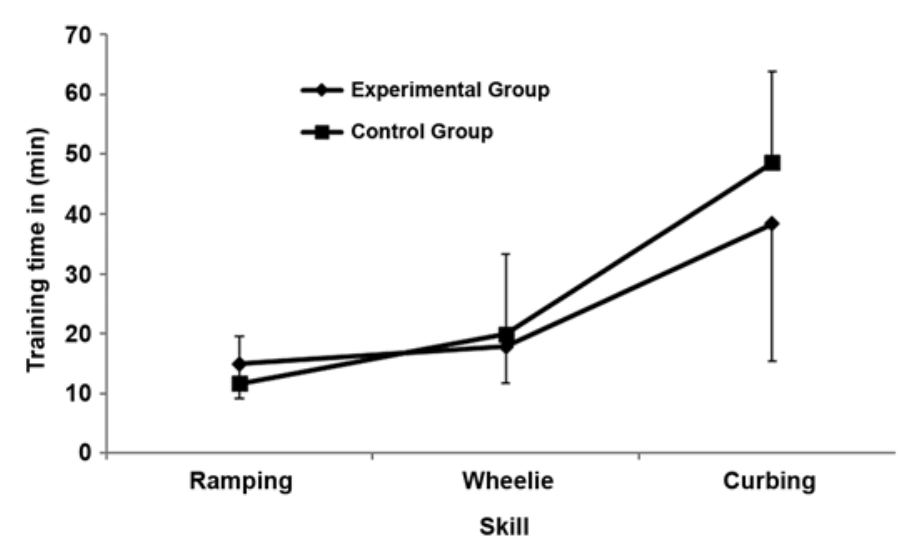

Figure.

Interaction of training time (means and standard deviations) on three advanced wheelchair skills between two groups. differ between the two groups on the three tests (Table 3). Although the experimental group consistently took less time to accomplish the wheelchair skill tests, the differences were fairly small (i.e., differences ranging from 0.04 to $0.46 \mathrm{~s}$, Table 3). Whether these small differences are clinically meaningful would require further investigations. On the wheelchair ramp skill, the experimental and control groups had exactly the same spotter intervention (0) and success rate $(100 \%)$ across all three tests (Table 4). That is, the conventional wheelchair training method and the IVF training were equally effective in skill training. Also, the two groups had very similar spotter interventions and success rates across the three tests on the wheelchair wheelie skill. Thus, the IVF training method may be as effective as the conventional method in training for the wheelie skill. There were no significant differences between the groups on the wheelchair curb skill on the competency and retention tests, but on the transfer test, the experimental group had significantly more spotter interventions $(6.08 \pm 1.38$ vs $4.63 \pm 1.09$ counts, $p<0.05)$ and a significantly lower performance success rate $(42.86 \% \pm$ $34.50 \%$ vs $82.14 \% \pm 18.90 \%, p<0.05)$ than the control group. These results suggest that the IVF training method may be less effective than conventional training for the wheelchair curb transfer test. However, the curbing skill training time with IVF was 20 percent less (38.35 vs $48.59 \mathrm{~min}$ ) than the training time with the conventional method. Wheelchair wheelie and curbing are challenging skills to master; Hosseini et al. reported that the success rates on a $30 \mathrm{~s}$ wheelie skill were 64 percent for paraplegic participants and 48.1 percent for tetraplegic participants, and the success rates for curbing were 22.2 to 49.3 percent for paraplegic participants and 12.2 to 41.5 percent for tetraplegic participants [20]. Success rates for the wheelie skill in the present study ranged from 77.86 to 100 percent. Kirby et al. reported that the success rates for curbing were 86 to 89 percent [18], which is similar to that reported in the present study. During the exit interview, 80 percent of the physical therapists and 70 percent of the participants indicated that if the verbal cues and key words can be added to the training videos models, the IVF training could be more effective.

\section{Comparisons Between Two Groups on Three Skills and Three Tests on Skill Performance Time, Spotter Intervention, and Successful Rate of Skill Performance}

The results of 2 (groups) $\times 3$ (skills) $\times 3$ (tests) repeated-measures ANOVA (Table 5) showed that both 
conventional wheelchair skill training and IVF training were effective skill training methods for individuals with SCI.

The skill performance time for ramping was significantly less $(p<0.01)$ than for wheelie and curbing, and the skill performance time for wheelie was significantly less than for curbing. There were significantly more spotter interventions for curbing than for ramping and wheelie $(p<0.01)$, and the rate of successful performance of ramping was significantly greater than that of curbing. Wheelchair ramping may be a skill that is relatively easy to learn, requires less spotting (safety), and has a higher success rate; thus, it should be learned first among these three wheelchair skills.

The skill performance time in the transfer test was significantly longer than the retention test. There were significantly more spotter interventions in the transfer test than those in the retention $(p<0.05)$ and competency $(p<0.05)$ tests, but no significant differences were found on the three tests in the rate of successful performance. The transfer test was the most difficult test since the wheelchair skills had to be performed in a new environment, requiring more adaptability.

The results of this study suggest that IVF used in learning advanced manual wheelchair skills may produce similar results as conventional physical therapy methods. With video feedback training, it took a little more time to train for ramping but less time to train for wheelie and curbing, which are more challenging wheelchair skills. Both conventional training and IVF training have some advantages and disadvantages in terms of training time, skill retention, and transfer. Physical therapists may consider using video feedback training as a complementary or alternative training method for these wheelchair skills.

\section{Limitations}

Several limitations must be addressed for the present study. First, the sample size is too small and may not have truly represented the entire SCI population. Given the small number of participants, the pairs were matched in an injury range within three intervals. Secondly, we did not separate the ascending and descending phases while assessing the ramping and curbing skills. Thirdly, the simulated curb height was $12.6 \mathrm{~cm}$ high, which is a little lower than a more standard one $(15 \mathrm{~cm})$. In addition, the wheelchair video models did not contain verbal cues or computer graphic indications of the key components required for performing the wheelchair skills. Future studies incorporating verbal cues and computer graphic indications with the video feedback would be warranted to enhance the effectiveness of the IVF training.

\section{CONCLUSIONS}

Findings of the study suggest that the use of IVF for learning advanced manual wheelchair skills may result in similar performance to the conventional physical therapy method. The use of IVF may be considered as an alternative training method for training patients with SCI in acquiring the wheelchair skills, especially when the availability of the caregivers to provide skill demonstration and feedback is of concern. Based on the degree of difficulty in mastering these three wheelchair skills, we may recommend that patients learn the ramp wheelchair skill first and then learn the wheelie and curbing or curbing and wheelie. Future studies of wheelchair skill training should include IVF models with verbal cues and computer graphic indications.

\section{ACKNOWLEDGMENTS}

\section{Author Contributions:}

Study concept and design: Y. T. Wang, W. Limroongreungrat, L. S. Chang.

Acquisition of data: W. Limroongreungrat, L. S. Chang.

Analysis and interpretation of data: X. Ke, Y. P. Chen.

Drafting of manuscript: Y. T. Wang, L. C. Tsai, L. S. Chang, J. Lewis. Critical revision of manuscript for important intellectual content:

Y. T. Wang, L. C. Tsai.

Statistical analysis: Y. T. Wang.

Obtained funding: Y. T. Wang, W. Limroongreungrat.

Administrative, technical, or material support: Y.T. Wang, L. S. Chang. Study supervision: Y. T. Wang.

Financial Disclosures: The authors have declared that no competing interests exist.

Funding/Support: This material was based on work supported by the National Institute on Disability and Rehabilitation Research, Rehabilitation Engineering Research Centers Mobility Center at the Georgia Institute of Technology (project H133E080003).

Additional Contributions: The authors acknowledged the guidance of Dr. Stephen Sprigle in this project and the assistance of Ms. Michelle Nemeth, Mr. Abhinandan Batra, and Mr. Yi Wu in coordinating subject intervention, data collection, and data management.

Institutional Review: Approved by Georgia State University and Shepherd Center Institutional Review Boards.

Participant Follow-Up: The authors do not plan to inform participants of the publication of this study. 


\section{REFERENCES}

1. DeVivo MJ, Go BK, Jackson AB. Overview of the national spinal cord injury statistical center database. J Spinal Cord Med. 2002;25(4):335-38. [PMID:12482178]

2. Best KL, Kirby RL, Smith C, MacLeod DA. Wheelchair skills training for community-based manual wheelchair users: A randomized controlled trial. Arch Phys Med Rehabil. 2005;86(12):2316-23. [PMID:16344029] http://dx.doi.org/10.1016/j.apmr.2005.07.300

3. Giesbrecht EM, Miller WC, Eng JJ, Mitchell IM, Woodgate RL, Goldsmith CH. Feasibility of the Enhancing Participation In the Community by improving Wheelchair Skills (EPIC Wheels) program: Study protocol for a randomized controlled trial. Trials. 2013;14:350. [PMID:24156396] http://dx.doi.org/10.1186/1745-6215-14-350

4. Wheelchair Skills Program (WSP). Version 4.2 [Internet]. Halifax (Canada): Dalhousie University; 2013 [updated 2013 May 24]. Available from:

http://www.wheelchairskillsprogram.ca/eng/documents/ WSTP Manual 4.2.4.pdf

5. Barton GJ, De Asha AR, van Loon EC, Geijtenbeek T, Robinson MA. Manipulation of visual biofeedback during gait with a time delayed adaptive Virtual Mirror Box. J Neuroeng Rehabil. 2014;11:101. [PMID:24917329] http://dx.doi.org/10.1186/1743-0003-11-101

6. Yoon JA, Koo BI, Shin MJ, Shin YB, Ko HY, Shin YI. Effect of constraint-induced movement therapy and mirror therapy for patients with subacute stroke. Ann Rehabil Med. 2014;38(4):458-66. [PMID:25229024] http://dx.doi.org/10.5535/arm.2014.38.4.458

7. Huang H, Wolf SL, He J. Recent developments in biofeedback for neuromotor rehabilitation. J Neuroeng Rehabil. 2006;3:11. [PMID:16790060] http://dx.doi.org/10.1186/1743-0003-3-11

8. Foo J, Paterson K, Williams G, Clark R. Low-cost evaluation and real-time feedback of static and dynamic weight bearing asymmetry in patients undergoing in-patient physiotherapy rehabilitation for neurological conditions. J Neuroeng Rehabil. 2013;10:74. [PMID:23849318] http://dx.doi.org/10.1186/1743-0003-10-74

9. Guadagnoli M, Holcomb W, Davis M. The efficacy of video feedback for learning the golf swing. J Sports Sci. 2002;20(8):615-22. [PMID:12190281] http://dx.doi.org/10.1080/026404102320183176

10. Janelle CM, Barba DA, Frehlich SG, Tennant LK, Cauraugh $\mathrm{JH}$. Maximizing performance feedback effectiveness through videotape replay and a self-controlled learning environment. Res Q Exerc Sport. 1997;68(4):269-79.

[PMID:9421839] http://dx.doi.org/10.1080/02701367.1997.10608008
11. Zetou E, Tzetzis G, Vernadakis N, Kioumourtzoglou E. Modeling in learning two volleyball skills. Percept Mot Skills. 2002;94(3 Pt 2):1131-42. [PMID:12186234] http://dx.doi.org/10.2466/pms.2002.94.3c.1131

12. Lee SW, Shin DC, Song CH. The effects of visual feedback training on sitting balance ability and visual perception of patients with chronic stroke. J Phys Ther Sci. 2013;25(5): 635-39. [PMID:24259819]

http://dx.doi.org/10.1589/jpts.25.635

13. Baudry L, Leroy D, Chollet D. The effect of combined selfand expert-modelling on the performance of the double leg circle on the pommel horse. J Sports Sci. 2006;24(10): 1055-63. [PMID:17115520] http://dx.doi.org/10.1080/02640410500432243

14. Hodges NJ, Chua R, Franks IM. The role of video in facilitating perception and action of a novel coordination movement. J Mot Behav. 2003;35(3):247-60. [PMID:12873840] http://dx.doi.org/10.1080/00222890309602138

15. Kernodle MW, Johnson R, Arnold DR. Verbal instruction for correcting errors versus such instructions plus videotape replay on learning the overhand throw. Percept Mot Skills. 2001;92(3 Pt 2):1039-51. [PMID:11565912] http://dx.doi.org/10.2466/pms.2001.92.3c.1039

16. McGraw-Hunter M, Faw GD, Davis PK. The use of video self-modelling and feedback to teach cooking skills to individuals with traumatic brain injury: A pilot study. Brain Inj. 2006;20(10):1061-68. [PMID:17060139] http://dx.doi.org/10.1080/02699050600912163

17. Schmidt J, Fleming J, Ownsworth T, Lannin NA. Video feedback on functional task performance improves self-awareness after traumatic brain injury: A randomized controlled trial. Neurorehabil Neural Repair. 2013;27(4):316-24. [PMID:23270921] http://dx.doi.org/10.1177/1545968312469838

18. Kirby RL, Bennett S, Smith C, Parker K, Thompson K. Wheelchair curb climbing: Randomized controlled comparison of highly structured and conventional training methods. Arch Phys Med Rehabil. 2008;89(12):2342-48. [PMID:18976980] http://dx.doi.org/10.1016/j.apmr.2008.04.028

19. Kirby RL, Gillis DJ, Boudreau AL, Smith C, Rushton P, Clark-Gallant L, Parker KE, Webber A. Effect of a highrolling-resistance training method on the success rate and time required to learn the wheelchair wheelie skill: A randomized controlled trial. Am J Phys Med Rehabil. 2008; 87(3):204-11, quiz 212-14. [PMID:18287817] http://dx.doi.org/10.1097/PHM.0b013e318164aa27

20. Hosseini SM, Oyster ML, Kirby RL, Harrington AL, Boninger ML. Manual wheelchair skills capacity predicts quality of life and community integration in persons with spinal cord injury. Arch Phys Med Rehabil. 2012;93(12):2237-43. 
JRRD, Volume 52, Number 4, 2015

[PMID:22684049]

http://dx.doi.org/10.1016/j.apmr.2012.05.021

Submitted for publication November 16, 2014. Accepted in revised form March 4, 2015.

This article and any supplementary material should be cited as follows:

Wang YT, Limroongreungrat W, Chang LS, Ke X, Tsai
LC, Chen YP, Lewis J. Immediate video feedback on ramp, wheelie, and curb wheelchair skill training for persons with spinal cord injury. J Rehabil Res Dev. 2015; 52(4):421-30.

http://dx.doi.org/10.1682/JRRD.2014.11.0286

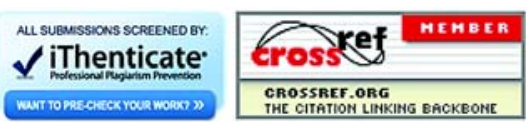

